УДК 662.01:338.28

\title{
ВОЗМОЖНОСТИ ОЦЕНКИ КОНКУРЕНТОСПОСОБНОСТИ УГЛЕДОБЫВАЮЩИХ ПРЕДПРИЯТИЙ ВОСТОЧНОГО ДОНБАССА
}

\author{
(C) 2012 г. A. A. Смахтина
}

\section{Южно-Российский государственный технический университет (НПИ)}

В статье рассматриваются проблемы, связанные с оценкой конкурентоспособности отечественных угледобывающих компаний и проведен анализ уровня конкурентоспособности угледобывающих предприятий Восточного Донбасса.

Ключевые слова: конкурентоспособность; угледобывающие предприятия; очзенка; Восточный Донбасс.

In the article author presents the examination of the actual problems in valuating the competitiveness of Russian coal-mining enterprises. The analysis of some coal-mining enterprises' competitiveness level in the Eastern Donbass is also presented.

Key words: competitiveness; coal mines; valuation; Eastern Donbass.

В отечественной и зарубежной литературе основным методом оценки уровня конкурентоспособности производственного предприятия является оценка конкурентоспособности продукта, производимого рассматриваемой компанией. На практике данную оценку провести наиболее легко, так как информация о потребительских свойствах и эксплуатационных характеристиках продуктов является доступной. При этом все методики оценки конкурентоспособности основываются на использовании типичных количественных и качественных показателей, обобщая при этом все производства и продукции, не отражая специфику производства.

Оценка конкурентоспособности угледобывающего предприятия - более сложная задача. Проблематичность такой оценки усугубляется невозможностью во многих случаях законными способами получить достоверную информацию о различных аспектах производственно-хозяйственной деятельности, как самого предприятия, так и отрасли в целом.

Вследствие этого представляет определенный интерес оценка изменения конкурентоспособности угледобывающего предприятия во времени без учета деятельности аналогичных предприятий (конкурентов). Безусловно, такая методика оценки носит ограниченный характер, так как показатели конкурентоспособности в подобном контексте, каждый в отдельности, характеризуют динамику изменения эффективности рыночной деятельности предприятия и не содержат информацию о ее позиции на рынке в долгосрочной перспективе.

При этом предложенная методика и использование неполной информации позволяет выявить сильные и слабые стороны в деятельности, проанализировать улучшение или ухудшение в целом рыночной позиции предприятия.

Оценка уровня конкурентоспособности угледобывающих предприятий представляет собой очень сложную работу, так как:

- во-первых, на конкурентоспособность угледобывающего предприятия влияет ряд показателей качества продукции, ценность добываемого угля;

- во-вторых, в России и более развитых странах в настоящее время, отсутствуют международные нормативно-правовые акты и документы по оценке конкурентоспособности угледобывающих предприятий;

- в-третьих, при оценке финансовой 
привлекательности угледобывающего предприятия не уделяется должного внимания инвестиционному потенциалу и инновационной активности. При этом ни одно министерство или ведомство, ни один вуз или НИИ в России комплексно не занимаются проблемами конкурентоспособности угледобывающих предприятий. Это привело к снижению конкурентоспособности России: в 2012 г. из 100 оцениваемых стран Россия переместилась с 66-го на 67-е место [1].

Исходя из сложности, особенностей и важности объекта оценки конкурентоспособности принципы и специфические показатели конкретных объектов формулируются в каждом конкретном случае. Так, в основу измерения конкурентоспособности добывающих предприятий Восточного Донбасса может быть положен метод оценки аналитических коэффициентов. Конкурентоспособность данных предприятий рекомендуется оценивать на основе интегрального показателя конкурентоспособности с учетом значимости количественных и качественных оценок эффективности деятельности предприятия.

Для оценки конкурентоспособности угледобывающего предприятия необходимо провести анализ ее состояния. Качество анализа будет высоким при его проведении с позиций системного подхода, в этом случае его анализ можно называть системным. Целью системного анализа угледобывающего предприятия является установление стратегических и тактических факторов повышения конкурентоспособности как самого предприятия, эффективности и устойчивости функционирования фирмы, так и выпускаемых товаров.

Проведение системного анализа конкурентоспособности организации включает в себя следующие этапы:

1. Анализ качества научного сопровождения системы стратегического менеджмента с точки зрения количества и глубины применяемых научных подходов и методов управления.

2. Анализ механизма действия закона конкуренции в отрасли, антимонопольного (антитрестовского) законодательства, формы (структуры) и силы конкуренции в отрасли.

3. Анализ качества управляемой подсистемы системы стратегического менеджмента в части формирования системы показа- телей качества и ресурсоемкости товаров, качества их сервиса, инфраструктуры рынка, организации анализа эффективности этих направлений деятельности и формирования мероприятий по их улучшению.

4. Анализ устойчивости функционирования организации.

5. Анализ качественных показателей деятельности предприятия.

6. Установление стратегических и тактических факторов повышения конкурентоспособности предприятия, эффективности и устойчивости функционирования организации для разработки на их основе ее стратегии. На этом этапе синтезируется вся предыдущая работа.

В настоящее время отсутствует общепринятая методика оценки конкурентоспособности организации. Вообще, в теоретическом плане проблема достижения конкурентоспособности различных объектов в условиях российской экономики в настоящее время не решается. При этом подходы к оценке конкурентоспособности не могут быть одними и теми же для стадий стратегического и тактического менеджмента. На стадии стратегического менеджмента (пространственный аспект) и первой функции управления (временной аспект) разрабатываются нормативы конкурентоспособности на длительный период, а на стадии тактического менеджмента выполняются работы по материализации у изготовителя и реализации на рынке стратегических нормативов конкурентоспособности, а также по корректировке этих нормативов. Поэтому при измерении конкурентоспособности организации на стадии стратегического менеджмента приоритет должен отдаваться динамическому подходу, прогнозированию будущих состояний в настоящем на базе прошлого.

По методике оценки конкурентоспособности угледобывающего предприятия разработаны следующие предложения:

- уровень конкурентоспособности считать как средневзвешенную величину по количественным показателям конкурентоспособности предприятия;

- отдельно проводить анализ эффективности деятельности организации исходя из конкурентоспособности и эффективности ее деятельности рынке; 
Таблица 1

Интегральная функция конкурентоспособности угледобывающих предприятий

\begin{tabular}{|c|c|c|c|c|c|c|c|c|}
\hline & 2004 & 2005 & 2006 & 2007 & 2008 & 2009 & 2010 & 2011 \\
\hline Шахта «Алмазная» & 175,77 & 4,64 & 29,32 & 335,05 & 15,42 & $-0,90$ & 1,53 & 10,07 \\
\hline Шахта «Гуковская» & $-6,21$ & $-4,30$ & $-3,34$ & 1,59 & 0,00 & 0,00 & 0,00 & 0,00 \\
\hline Шахта «Дальняя» & $-85,59$ & $-18,84$ & $-9,50$ & 0,00 & $-3,05$ & $-3,15$ & 4,04 & 7,00 \\
\hline $\begin{array}{l}\text { Шахта } \\
\text { «Замчаловская» }\end{array}$ & $-13,42$ & $-8,13$ & $-12,04$ & $-8,48$ & $-14,04$ & $-21,05$ & $-29,83$ & $-22,12$ \\
\hline Шахта «Западная» & 9,99 & 11,09 & 12,08 & 12,37 & 13,35 & 16,01 & 9,11 & 14,61 \\
\hline Шахта «Обуховская» & 8,32 & 13,08 & 11,93 & 12,12 & 9,56 & 8,31 & 9,21 & 11,21 \\
\hline Шахта «Ростовская» & 13,51 & 13,77 & 15,76 & 9,65 & 8,87 & 10,59 & 11,02 & 13,38 \\
\hline Шахта №410 & $-10,09$ & $-6,98$ & $-7,50$ & $-2,12$ & $-4,24$ & $-2,48$ & $-2,14$ & 0,53 \\
\hline Шахта «Садкинская» & 5,86 & 9,32 & 6,97 & 8,12 & 3,04 & 0,08 & 1,70 & 4,15 \\
\hline $\begin{array}{l}\text { Шахта «Шерлов- } \\
\text { ская-Наклонная» }\end{array}$ & $-3,50$ & $-2,95$ & $-3,26$ & $-3,26$ & $-7,08$ & $-2,91$ & $-3,64$ & $-2,66$ \\
\hline $\begin{array}{l}\text { Шахта } \\
\text { «Обуховская №1» }\end{array}$ & 4,03 & 3,89 & 5,93 & 7,88 & 5,91 & 6,19 & 8,46 & 8,78 \\
\hline $\begin{array}{l}\text { Шахта } \\
\text { «Кадамовская» }\end{array}$ & 4,86 & 5,12 & 7,92 & 5,95 & 4,18 & 6,47 & 7,21 & 9,45 \\
\hline $\begin{array}{l}\text { Открытое акционер- } \\
\text { ное общество «Шах- } \\
\text { та «Восточная» }\end{array}$ & $-35,01$ & $-38,15$ & $-39,40$ & $-48,33$ & $-59,90$ & $-87,88$ & $-94,86$ & 0,00 \\
\hline $\begin{array}{l}\text { Открытое акционер- } \\
\text { ное общество } \\
\text { «Шахта «Антрацит» }\end{array}$ & $-14,40$ & $-20,42$ & $-26,18$ & $-38,06$ & $-64,98$ & $-78,97$ & $-72,21$ & $-62,17$ \\
\hline $\begin{array}{l}\text { Общество с ограни- } \\
\text { ченной ответствен- } \\
\text { ностью «Ростовская } \\
\text { угольная компания» }\end{array}$ & $-33,09$ & $-34,28$ & $-35,03$ & $-0,12$ & $-13,26$ & $-23,13$ & 31,95 & $-32,03$ \\
\hline
\end{tabular}


- отдельно считать интегральный показатель (функцию) устойчивости функционирования организации;

- прогнозировать уровень конкурентоспособности на ближайшие 5 лет.

Проведем анализ уровня конкурентоспособности угледобывающих предприятий Восточного Донбасса за последние 8 лет на основе разработанных автором количественных и качественных показателей. Можно установить степень конкурентоспособности шахт и определить срок снижения конкурентоспособности на ближайшую перспективу, предложив стратегии развития предприятий для повышения или поддержания их конкурентоспособности.

Как описывалось ранее, на оценку уровня конкурентоспособности угледобывающих предприятий Восточного Донбасса влияют пять показателей:

- рентабельность продукции;

— ценность добываемого угля;

— инвестиционный потенциал;

- ущерб окружающей среде; ности.

- коэффициент инновационной актив-

В результате произведенных расчетов интегральная функция [2] выглядит следующим образом:

$$
\begin{gathered}
f_{c}=0,3962 \cdot n_{1}+2,64 \cdot n_{2}+0,075 \cdot n_{3}+ \\
+1,19 \cdot n_{4}+0 \cdot n_{5},
\end{gathered}
$$

где $f_{c}$ - интегральный показатель оценки конкурентоспособности; $n_{1}$ - рентабельность продукции угледобывающих предприятий; $n_{2}$ - ценность добывающего угля; $n_{3}$ - инвестиционный потенциал угледобывающих предприятий; $n_{4}$ - ущерб, наносимый окружающей среде угледобывающими предприятиями; $n_{5}-$ коэффициент инновационной активности.

Рассчитав данные показатели и вычислив интегральную функцию можно оценить степень конкурентоспособности шахт (табл. 1).

Степень конкурентоспособности угледобывающих предприятий Ростовской области можно признать неудовлетворительной.
Большинство шахт имеют проблемы с рентабельностью, инвестиционным потенциалом, с инновационным потенциалом (заметим, что только в 2009 г. появились первые инвестиционные вложения в инновационные технологии в данной отрасли) [3]. Динамика инвестиций в инновационную деятельность, как со стороны предприятий, так и со стороны частных инвесторов и государства остается на низком уровне, что приводит к снижению уровня конкурентоспособности предприятий и их инвестиционной привлекательности, как со стороны отечественных, так и со стороны иностранных инвесторов.

В условиях развивающегося кризиса в европейских странах и стагнации экономики страны, если угледобывающие предприятия не будут уделять особое внимание перечисленным выше проблемам, ухудшение условий для ведения производственной деятельности может привести к банкротству предприятий и ухудшению экономической ситуации в Ростовской области. Это впоследствии может привести к закрытию моногородов, т. к. данные предприятия являются градообразующими.

\section{Литература}

1. Парфенщев C. B. Формирование устойчивых перспектив развития угледобывающего производства при государственно-частном партнерстве: Автореф. дисс. на соиск. уч. степ. канд. экон. наук. - Москва, 2012.

2. Altman E. I., Marco G., Varetto F. Corporate distress diagnosis: comparisons using linear discriminant analysis and neural networks (the Italian experience). // J. Banking Fin. 1994. — №18 (3). - Рp. 505-529.

3. Лемяскин А. А. Методические основы оценки перспектив развития угледобывающих предприятий в моногородах. // Горный информационно-аналитический бюллетень. — 2011. — №5. - C. 175-178. 


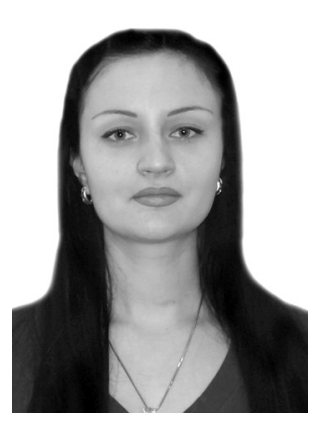

Анна Анатольевна Смахтина - старший преподаватель кафедры «Экономика и право» Шахтинского института (филиала) ЮРГТУ (НПИ).

Anna Anatoliyevna Smakhtina - senior lecturer of the SRSTU (NPI) Shakhty institute (branch) «Economics and Law» department.

346500, Ростовская обл., Шахты, пл. Ленина, 1

1 Lenina sq., 346500, Shakhty, Rostov reg., Russia

Тел.: +7 (8636) 22-20-36, факс: +7 (8636) 22-30-88, e-mail: siurgtu@itsinpi.ru 